\title{
On Durability
}

\section{I'm no economist, but I have become convinced that our consuming societies, at least in the economically "developed" world, have become sources of harm to}

ourselves and our planet. One has only to read about single-use products (for example, plastic bags and bottles, packaging material, straws, paper cups, gift wrapping) or shortuse products (for example, mobile phones and other electronics) to recognize this is a serious and huge problem. This consumption drives a significant part of the economy. It isn't just relatively modest per-item costs either. We probably don't use automobiles as long as we could (and should) before we want the latest and greatest. There is a category of goods called durable goods that typically have longer usage. Washing machines, refrigerators, ovens, stove tops, fireplaces, utensils, and dishes fall into this category. This line of reasoning makes me wonder whether we could shift the pollution needle toward longer use products as substitutes.

While it is not a solution to all shortuse goods, software can contribute new functionality without requiring replacement of the underlying hardware. A good example of this is found with the Tesla electric cars. They are heavily dependent on software for their operation and upgrades with new functionality are frequent and unobtrusive. One wonders whether this concept could increase the useful lifetime of at least some products. Of course, the idea is not useful for nonprogrammable goods, like plastic bottles and paper towels!

However, it is worth thinking about the design of products to maximize ease of repair, durability, and perhaps also repurposing. For example, imagine glass jars designed to be useful as cups as well as being reused as containers. Remember Mason jars for preserving fruits and vegetables for the winter? Or the glass bottles that soft drinks came in that were redeemed for two cents and reused by the bottling companies? What about reversible clothing? I remember saving animal fat and turning it into soap (OK, I suppose that would be a bit extreme today). None of these are new ideas but they make me wonder about increasing the value of durability and decreasing the attraction of throwaway products.

I guess that changing the value system is a form of social engineering and not so easy. One would look for incentives for consumers and producers to induce such a change. It's also important to understand how such a trend would affect the economy. Consumption drives production and expenditure. Would the "velocity of money" change significantly in a society that values durability? How might that affect economic indicators such as gross domestic product (GDP)? Would this change income and wealth inequality? Would it affect the way in which companies are valued? Profit growth as a metric of corporate value may induce behaviors that are not conducive to societal wellbeing if the side effects are pollution, waste, and externalizing costs (for example, shipping trash out of the country). I'm not qualified to answer any of these questions, but they all seem to me worthy of asking.

Returning to the possible role of software and computing, one wonders whether these tools could be applied to the design of durable and reusable products? I am thinking not only of programmable goods but of other products that would benefit from flexible designs. It used to be the case that repair of products and inventory of spare parts added value to the products. Products today seem to be designed not for repair but replacement. Could we apply our machine learning and other software tools to make products more repairable rather than less? It is possible that modularity of design could play a role although it might increase the cost of production but perhaps reduce the lifetime cost of use. We have tried to make products recyclable but this seems to have been only partially effective. Perhaps a return to durability is worthy of consideration. Of course, I may have been influenced by the fact that I live in a house full of antiques, some of which are over 200 years old-not counting me. At some point, the value of used furniture goes from zero to ridiculously expensive.

Vinton G. Cerf is vice president and Chief Internet Evangelist at Google. He served as ACM president from 2012-2014. 